\title{
Clonal replacement of epidemic KPC- producing Klebsiella pneumoniae in a hospital in China
}

\author{
Yuying Liang ${ }^{\dagger}$, Xiuyun Yin ${ }^{\dagger}$, Lijun Zeng and Shuiping Chen ${ }^{*}$
}

\begin{abstract}
Background: Klebsiella pneumoniae is a frequent nosocomial pathogen causing difficult-to-treat infections worldwide. The prevalence of Klebsiella pneumoniae carbapenemase (KPC)-producing Klebsiella pneumoniae (KPC-KP) is increasing in China. The aim of this study was to investigate the molecular epidemiology of KPC-KP in a nosocomial outbreak.

Methods: Fifty-four KPC-KP isolates were consecutively collected between November 2013 and August 2014 during a KPC-KP outbreak in a tertiary care hospital in Beijing, China. Antimicrobial susceptibility was determined by agar dilution. Carbapenemase, extended-spectrum $\beta$-lactamase, 165 rRNA methylase, AmpC $\beta$-lactamase, and plasmidmediated quinolone resistance determinants were detected by PCR amplification. The genetic relatedness of isolates was analyzed by pulsed-field gel electrophoresis and multi-locus sequence typing.

Results: All isolates belonged to ST11 except one isolate which was identified as a new sequence type (ST2040). PFGE profile of genomic DNA revealed seven clusters, of which cluster A and C dominated the KPC-KP outbreak and cluster A was replaced by cluster C during the outbreak. PFGE of genomic DNA, S1-PFGE of plasmids, replicon typing, and drug resistant characteristics showed that clonal spread occurred during the outbreak. When compared with isolates within cluster $A$, all isolates in cluster $C$ harbored $r m t B$ and showed higher level of resistance to cefepime, amikacin, tobramycin, and tigecycline.

Conclusion: We reported a nosocomial outbreak of KPC-KP with clonal replacement and a new sequence type (ST2040) of KP. High degree of awareness and surveillance of KPC-KP should be given to avoid potential outbreaks, especially in ICU wards.
\end{abstract}

Keywords: Klebsiella pneumoniae, Carbapenemase, Clonal replacement, Epidemiology, Antimicrobial resistance

\section{Background}

Carbapenem-resistant Klebsiella pneumoniae (KP) has spread worldwide and become a major public health threat in health care facilities [1], and the mortality could reach up to $40-50 \%$ [2]. According to an antimicrobial resistance surveillance networks in China (CHINET), the rate of carbapenem-resistant KP escalated from $0.7 \%$ in 2006 to $10 \%$ in 2013 [3], which is mainly due to the rapid dissemination of Klebsiella pneumoniae carbapenemase (KPC)-producing Klebsiella

\footnotetext{
* Correspondence: shpchen@hotmail.com

${ }^{\dagger}$ Equal contributors

Department of Laboratory Medicine, Affiliated hospital of Academy of Military Medical Sciences, Beijing, People's Republic of China
}

pneumoniae (KPC-KP) [4]. The bla $a_{\mathrm{KPC}}$ gene can be disseminated by both clonal spread and horizontal plasmid transfer [5]. In China, KPC-KP was firstly identified in 2007 [6]. Since then, this pathogen has been identified in several provinces and ST11 has been demonstrated to be the dominant clone [4, 7-16]. Nosocomial outbreaks of KPC-KP were also described previously [14, 17, 18]. However, clonal replacement of epidemic KPC-KP has not been reported in China or abroad.

Here, we reported a nosocomial outbreak of KPC-KP with clonal replacement in our hospital, which involved 54 consecutive patients and mainly occurred in ICU wards. The drug resistance and epidemiologic features of KPC-KP were also described. 


\section{Methods}

\section{Patients and bacterial isolates}

All Carbapenem-resistant KP strains, which were collected between November 2013 and August 2014 in this study, were isolated from different clinical wards of our tertiary care hospital with 1500 beds. Species were identified by the Vitek 2 system, followed by $16 \mathrm{~S}$ rDNA sequencing. Crude mortality was defined as death during hospitalization. Infection-related mortality was defined as death only as a direct consequence of KPC-KP infection during hospitalization. A KPC-KP outbreak was defined as two or more laboratory-confirmed patients that were temporally related, epidemiologically linked, and infected by the same KP variant.

\section{Detection of antibiotic resistance genes}

Isolates exhibiting resistance to at least one of the carbapenems (imipenem or ertapenem) were evaluated for the presence of $b l a_{\mathrm{KPC}}$ by PCR and sequencing as described previously $[19,20]$. All of the KPC-positive isolates were subjected to PCR amplification and sequencing for the presence of carbapenemase genes $\left(b l a_{\mathrm{GES}}\right.$, bla $a_{\mathrm{SME}}$, bla $a_{\mathrm{IMI}}, b l a_{\mathrm{BIC}}, b l a_{\mathrm{NDM}}, \quad b l a_{\mathrm{IMB}}$ bla $a_{\mathrm{VIM}}, b l a_{\mathrm{SIM}}$, and $\left.b l a_{\mathrm{SPM}}\right)[19,20]$, extended-spectrum $\beta$-lactamase genes (bla $a_{\mathrm{TEM}}, b l a_{\mathrm{SHV}}, b l a_{\mathrm{CTX}-\mathrm{M}}$, and bla $\left.a_{\mathrm{OXA}-48-\text { like }}\right)$ [21-23], 16S rRNA methylase genes $(\operatorname{arm} A, r m t A, r m t B, r m t C$, $r m t D, r m t E$, and $n p m A)[24,25]$, AmpC $\beta$-lactamase genes $\left(b l a_{\mathrm{ACC}}, b l a_{\mathrm{FOX}}, b l a_{\mathrm{MOX}}, b l a_{\mathrm{DHA}}, b l a_{\mathrm{CIT}} / b l a_{\mathrm{SPM}}\right.$, and $\left.b l a_{\mathrm{EBC}}\right)$ [26], and plasmid-mediated quinolone resistance (PMQR) genes ( $q \eta r A, q n r B, q n r C$, qnrS, qepA, $\operatorname{acc}\left(6^{\prime}\right)-I b-c r, o q x A$, and $\left.o q x B\right)$ [27].

\section{Antimicrobial susceptibility testing}

Susceptibility tests were performed using the Vitek 2 system and the AST-GN card. MICs of various antimicrobials were determined by agar dilution method and results were interpreted according to the criteria recommended by CLSI (2014) [28].

\section{Pulsed-field gel electrophoresis (PFGE) analysis}

The clonal relatedness of KP isolates were analyzed by PFGE as described previously [29]. Prepared genomic DNA was digested using XbaI restriction enzyme on all clinical isolates. The banding patterns were analyzed by the BioNumerics software. The genetic similarity was calculated by dice coefficients and dendrograms were constructed by the unweighted pair group of arithmetic average. The analysis parameters were based on $1.5 \%$ tolerance values. Clusters were defined as DNA patterns sharing $\geq 85 \%$ similarity. Plasmid profiling was performed by PFGE of total bacteria genome DNA cut with nuclease $\mathrm{S} 1$.
Multi-locus sequence typing (MLST) analysis

Genotyping was further determined by MLST analysis. Standard DNA amplification and sequencing of seven housekeeping genes (gapA, infB, $m d h$, pgi, phoE, rpoB, and $\operatorname{ton} B$ ) were performed as described previously [30]. The allele sequences and sequence types (ST) were identified at http://bigsdb.web.pasteur.fr/klebsiella/klebsiella.html.

\section{PCR-based replicon typing (PBRT)}

To determine the plasmid incompatibility groups (F, FIA, FIB, FIC, HI1, HI2, I1-Ic, L/M, N, P, W, T, A/C, K, B/O, $\mathrm{X}, \mathrm{Y}$, and FII), PBRT were carried out in all isolates as described previously [31].

\section{Conjugation experiments}

The conjugation experiments were performed by using azide-resistant E.coli 553 as the recipient strain. Cultures of donor and recipient cells in logarithmic phase $(0.5 \mathrm{ml}$ of each) were added to $4 \mathrm{ml}$ of fresh Luria-Bertani broth and were incubated overnight without shaking. The transconjugants were selected on Mueller-Hinton agar plates containing $100 \mu \mathrm{g} / \mathrm{ml}$ ampicillin and $300 \mu \mathrm{g} / \mathrm{ml}$ sodium-azide. Antibiotic resistance genes and replicon typing were performed as described previously in this study.

\section{Statistical analysis}

All statistical analysis were performed using the SPSS software package version 20.0. Continuous variables (age and Charlson score) were summarized as medians and were compared using non-parametric Mann-Whitney U test. Categorical variables were summarized as percentages and were compared using the pearson chi-square test. A $p$-value of less than 0.05 was considered statistically significant.

\section{Results \\ Description of isolates}

A total of 54 non-duplicate KPC-KP isolates were included in this study. All patients, where the 54 isolates were isolated from, were identified as clinical infections based on the isolation of KPC-KP from clinical samples and medical diagnosis established by physicians according to the clinical manifestations and the antibacterial effects. The predominant type of samples from which $\mathrm{KPC}$ isolates were isolated was sputum $(n=41,75.9 \%)$, followed by bronchoalveolar lavage fluid $(n=5,9.3 \%)$, blood $(n=4,7.4 \%)$, secretions $(n=2,3.7 \%)$, urine ( $n=1,1.9 \%)$, and peritoneal fluid $(n=1,1.9 \%)$. Of note, $77.8 \%(42 / 54)$ of isolates were isolated from patients in two ICU wards (ICU-1, respiratory medicine department; ICU-2, department of critical care medicine), and remaining $22.2 \%(12 / 54)$ of isolates were isolated from 
other seven medical wards. Specifically, the ICU-1 ward (with 14 beds) and ICU-2 ward (with 12 beds) belonged to two departments and were located in two different buildings with a distance of about $100 \mathrm{~m}$. There were no intercommunications of patients, staffs, and medical instruments between the two ICU wards. Patients in the two ICU wards were scattered in patient rooms or beds.

\section{Genotypic investigation of resistance}

Among the 54 KPC-KP (bla $\left.a_{\mathrm{KPC}-2}\right), 1.9 \%$ (1/54) carried $b l a_{\mathrm{SHV}-11}, 48.1 \%(26 / 54)$ carried $b l a_{\mathrm{SHV}-11}$ and $b l a_{\mathrm{TEM}-1}$, and the remaining $50 \%(27 / 54)$ carried $b l a_{\mathrm{TEM}-1}, b l a_{\mathrm{SHV}}$ (bla $a_{\mathrm{SHV}-1}, b l a_{\mathrm{SHV}-2}, b l a_{\mathrm{SHV}-11}$ and $\left.b l a_{\mathrm{SHV}-12}\right)$, and $b l a_{\mathrm{CTX}}$ $\left(b l a_{\mathrm{CTX}-\mathrm{M}-3}\right.$ and $\left.b l a_{\mathrm{CTX}-\mathrm{M}-14}\right)$. Among $r m t B$-positive KPC-KP (RP-KP) isolates $(n=20), 45.0 \%(9 / 20)$ of isolates carried $q n r S$ and $50.0 \%(10 / 20)$ of isolates carried $q n r S$ and $a c c\left(6^{\prime}\right)-I b-c r$. However, among $r m t B$-negative KPC-KP (RN-KP) isolates $(n=34)$, only $5.9 \%(2 / 34)$ of isolates carried $a c c\left(6^{\prime}\right)-I b-c r$ and $8.8 \%(3 / 34)$ of isolates carried $q n r S$ and $a c c\left(6^{\prime}\right)-I b-c r$. Resistance genes encoding class $\mathrm{B}$ carbapenemase $\left(b l a_{\mathrm{NDM}}, b l a_{\mathrm{SIM}}, b l a_{\mathrm{IMP}}\right.$ bla $a_{\mathrm{VIM}}$, and $\left.b l a_{\mathrm{SPM}}\right)$ and AmpC $\beta$-lactamase (bla $a_{\mathrm{ACC}}$, bla $_{\mathrm{FOX}}, b l a_{\mathrm{MOX}}, b l a_{\mathrm{DHA}}, \quad b l a_{\mathrm{CIT}} / b l a_{\mathrm{SPM}}$, and $\left.b l a_{\mathrm{EBC}}\right)$ were not detected in any of the isolates.

\section{Molecular typing}

Through KP MLST analysis, 98.1\% (53/54) of isolates belonged to ST11 (allelic profile 3-3-1-1-1-1-4). Only one isolate was identified as a new ST (ST2040, allelic profile 3-3-1-1-1-1-326), which only differed from ST11 with a substitution in the $\operatorname{ton} B$ allele. PFGE identified two major clusters (A, C) among 54 isolates. The cluster $\mathrm{A}$ and $\mathrm{C}$ consisted of $27 \mathrm{RN}-\mathrm{KP}$ isolates and 20 $\mathrm{RP}-\mathrm{KP}$ isolates, respectively. The other seven RN-KP isolates were classified into the cluster B, D, E, F, and G (Fig. 1).

\section{Distribution of plasmid replicons}

PBRT revealed that $55.6 \%(30 / 54)$ and $37.0 \%(20 / 54)$ of KP isolates contained IncFIIAs and IncFII, respectively. Specifically, $96.3 \%(26 / 27)$ of isolates in cluster A contained IncFIIAs, and 100\% (20/20) of isolates in cluster $\mathrm{C}$ contained IncFII. After sequencing, the IncFIIAs confirmed in this study was identified as a new subtype of IncFII, which was characterized with low nucleotide identity (90\%) when compared with the IncFIIAs replicon of Salmonella virulence plasmids.

\section{Conjugation experiments}

Five predominant isolates (KPN-01, KPN-16, KPN-34, $\mathrm{KPN}-60$, and KPN-69) in cluster A and 11 predominant isolates (KPN-50, KPN-66, KPN-70, KPN-71, KPN-73, KPN-75, KPN-79, KPN-84, KPN-87, KPN-88, and KPN89 ) in cluster $C$ were used in conjugation experiments.
Of the 16 tested isolates, only one isolate (KPN-69) in cluster $\mathrm{A}$ and four isolates (KPN-50, KPN-66, KPN-70, and $\mathrm{KPN}-88$ ) in cluster $\mathrm{C}$ yielded transconjugants. As for replicon type, IncFIIAs and IncFII were confirmed in transconjugants (IncFIIAs: KPN-69; IncFII: KPN-50 and KPN-70). The transconjugant of KPN-69 harbored $b l a_{\mathrm{KPC}-2}$ and $b l a_{\mathrm{TEM}-1}$. The transconjugant of KPN-50 and KPN-70 harbored $b l a_{\mathrm{KPC}-2}, b l a_{\mathrm{TEM}-1}, b l a_{\mathrm{CTX}-\mathrm{M}}$, and $r m t B$. The transconjugant of KPN-66 and KPN-88 harbored $b_{a_{\mathrm{SHV}-11}}$ (or bla $a_{\mathrm{SHV}-12}$ ), bla $a_{\mathrm{CTX}-\mathrm{M}}$, and $q n r S$.

\section{Outbreak}

The epidemic curve revealed five phases (Fig. 2): phase 1 (Nov 2013 to Mar 2014), fewer cases (< 5 cases per month) mainly caused by cluster A; phase 2 (Apr 2014), a small outbreak ( $\geq 5$ cases per month) caused by cluster A; phase 3 (May 2014), a small outbreak caused by four different clusters; phase 4 (Jun 2014), a small outbreak caused by cluster C; phase 5 (Jul 1014 to Aug 2014), fewer cases mainly caused by cluster $C$. Of note, cluster A was replaced by cluster $\mathrm{C}$ during this $\mathrm{KP}$ outbreak. 85.2\% (23/27) of isolates in cluster A contained one plasmid with IncFIIs replicon which harbored resistance gene $b l a_{\mathrm{KPC}}, b l a_{\mathrm{TEM}}$, and $b l a_{\mathrm{SHV}}$. According to PFGE of genomic DNA, S1-PFGE of plasmids, replicon typing, and drug resistant characteristics (Fig. 1), two main groups in cluster $\mathrm{C}$ were suggested to be derived from different origins, of which one group consisted of isolates from the ICU ward of respiratory department (ICU-1) and the other group consisted of strains from the ICU ward of department of critical care medicine (ICU-2). 75\% (9/12) of isolates in the former group mainly contained three plasmids with IncFII replicon which harbored $b l a_{\mathrm{KPC}-2}, \quad b l a_{\mathrm{TEM}-1}, \quad b l a_{\mathrm{SHV}-11}$ (or $\left.b l a_{\mathrm{SHV}-12}\right), b l a_{\mathrm{CTX}-\mathrm{M}-14}, a c c\left(6^{\prime}\right)-I b-c r, q u r S$, and $r m t B$. However, all strains $(n=7)$ in the latter group contained two plasmids with FII replicon which harbored $b l a_{\mathrm{KPC}-2}, b l a_{\mathrm{TEM}-1}, b l a_{\mathrm{SHV}-11}$ (or $\left.b l a_{\mathrm{SHV}-12}\right), b l a_{\mathrm{CTX}-\mathrm{M}-14}$, $q n r S$, and $r m t B$. Specifically, clonal replacement (from cluster A to cluster C) occurred in ICU wards, especially in ICU-1 (Fig. 1).

\section{Antibiotic susceptibility}

Resistance rates in cluster C (RP-KP, $n=20$ ) were $100 \%$ to ampicillin, piperacillin/tazobactam, cefoxitin, cefepime, aztreonam, imipenem, amikacin, gentamycin, tobramycin, ciprofloxacin, levofloxacin, furantoin, sulfamethoxazole, and $40.0 \%(8 / 20)$ to tigecycline. However, resistance rates in cluster $\mathrm{A}(\mathrm{RN}-\mathrm{KP}, n=27)$ against aforementioned antibiotics were 100\% (27/27), 96.3\% (26/27), 92.6\% (25/27), 22.2\% (6/27), 100\% (27/27), 100\% (27/27), 0 (0/27), $88.9 \%$ (24/27), $7.4 \%$ (2/27), $100 \%$ (27/27), 100\% (27/27), 100\% (27/27), and 100\% (27/27), respectively, as well as $0(0 / 27)$ to tigecycline, which was 


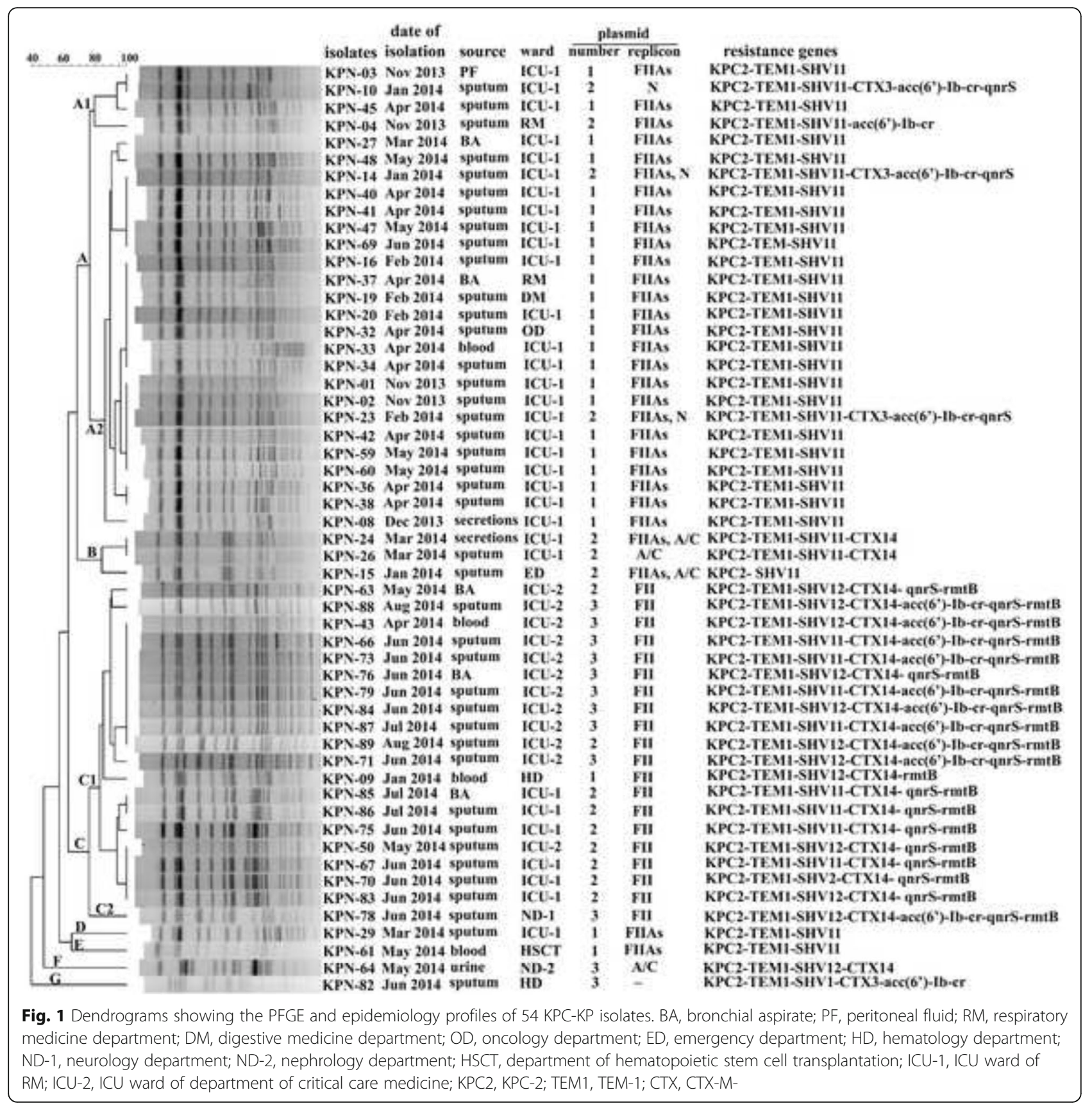

characterized with significantly lower resistance rates against cefepime ( $22.2 \%$ vs $100 \%$ ), amikacin (0 vs $100 \%)$, tobramycin ( $7.4 \%$ vs $100 \%)$, and tigecycline (0 vs $40.0 \%$ ) when compared with cluster $\mathrm{C}(p<0.05)$.

\section{Mortality discrepancy between clones}

Medical records revealed that there were no significant differences in gender (male percentage, $81.5 \%$ vs $70.0 \%$; median age, 75 vs 77; median Charlson scores, 6.0 vs 6.0; patient distributions (from ICU wards or transferred from ICU wards), $92.6 \%$ vs $95 \%$ ) in patients between cluster A $(n=27)$ and cluster $C(n=20)$. As for the crude mortality, it was significantly higher in cluster $\mathrm{C}$ than those in cluster A $(80.0 \%$ vs $51.9 \%, p<0.05)$. The infection-related mortality in cluster $\mathrm{C}$ was higher than those in cluster A although the difference was statistically nonsignificant ( $25.0 \%$ vs $14.8 \%, p>0.05)$.

\section{Discussion}

KPC-KP outbreaks have been previously reported in several provinces of China [4, 7-16]. Compared with Western countries, the prevalence of KPC-KP in China 


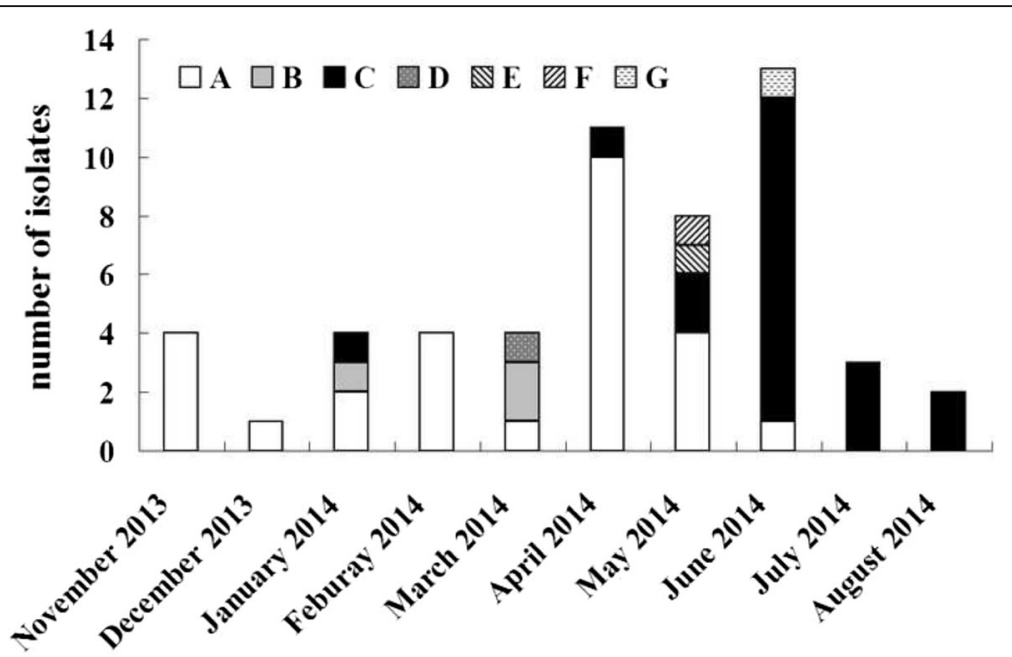

Fig. 2 Distribution of KPC-KP isolates by month and PFGE clusters. A to G were designated as PFGE clusters as described in Fig. 1.

is relatively low (2.9\%), as described in a 4000-bed tertiary care hospital [32]. However, KPC-KP is an increasing cause for great clinical concern due to its high antibiotic resistance and pathogenicity. In this study, a nosocomial outbreak caused by KPC-KP is described. As shown in Fig. 1, the first clonal replacement of epidemic KPC-KP occurred in ICU wards is confirmed by PFGE of genomic DNA, S1-PFGE of plasmids, replicon typing, and drug resistant characteristics. RP-KP also seems to have a higher dissemination advantage over RN-KP. Although this outbreak was severe in the ICU wards, it was terminated by effective measures, such as hand hygiene intervention, patient isolation, and environmental cleaning. This study suggests that continuous surveillance system and strict infection control measures are necessary and urgent to prevent the spread or outbreak of KPC-KP in health care facilities. It is noteworthy that bacterial culture and susceptibility test require 3-5 days and outbreak might occur during this period of time. Thus, rapid identification of the pathogens is crucial in the active surveillance culture program. On the other hand, considering that colonization frequently precedes infection, early identification of colonized cases might also reduce infections and potential outbreaks.

Although KPC-KP isolates have been identified worldwide, the spread has been proved to be caused by the dominant KP clones (ST258 and ST11). In China, ST11 is the dominant clone of KPC-KP [4]. Some new sequence types of KP have also been frequently described $[17,33]$. Here, we reported a new sequence type (ST2040). Compared with the majority of isolates in cluster C (ICU-2), this clone only contains two plasmids (Fig. 1). During the outbreak period, the new ST2040 was only isolated once and didn't become the epidemic strain. Although resistances are proved to be associated with reduced fitness and virulence of pathogens [34, 35], the clinical resistant KP isolates could survive in those high-density antibiotic environments (health care facilities and day care centers). Thus, as a multi-drug resistant clone, the fitness and pathogenicity of ST2040 might need to be investigated further.

The most frequently encountered ESBLs are TEM-, SHV-, and CTX-M-type $\beta$-lactamases. The bla $a_{\mathrm{CTX}-\mathrm{M}}$, of which prevalence is increased in KP, is carried mainly by IncFII-type plasmids [36]. In this study, the $b l a_{\mathrm{CTX}-\mathrm{M}}$ genes in isolates are also carried by IncFII-type plasmids and could be transferred by conjugation. On the contrary, IncFIIAs plasmids (a new replicon subtype), which harbor $b l a_{\mathrm{KPC}-2}, b l a_{\mathrm{TEM}-1}$, and $b l a_{\mathrm{SHV}-11}$ in isolates of cluster A, seems to be hard to be conjugative.

In this study, $100 \%(54 / 54)$ of isolates are positive for $b l a_{\mathrm{SHV}}$, consistent with the hypothesis that chromosomal bla $a_{\mathrm{SHV}}$ is ubiquitous in KP [37]. The majority of chromosomal SHV, including SHV-1, SHV-11, and its close relatives, are non-ESBLs enzymes. However, most of ESBLs-type SHV enzymes are plasmid-borne. In this study, the prevalence of ESBLs-type SHV enzymes (SHV-2 or SHV-12) and CTX-M enzymes in cluster C is significantly higher than those in cluster A $(60 \%(12 / 20)$ vs $0(0 / 27,100 \%(20 / 20)$ vs $11.1 \%(3 / 27))$. Thus, higher prevalence of cefepime-resistance $\mathrm{KP}$ in cluster $\mathrm{C}$ might be attributed to the fact that more isolates carry ESBLs enzymes.

PMQR determinants are increasingly reported in $\mathrm{KP}$ [14]. In this study, most $(86.7 \%, 13 / 15)$ of the $a c c\left(6^{\prime}\right)-I b$ cr-positive isolates also carry qnrS (Fig. 1). However, two transconjugants from donor isolates (KPN-66 and KPN88) co-harbored qnrS and $a c c\left(6^{\prime}\right)-I b-c r$ only carry qnrS, but no $a c c\left(6^{\prime}\right)-I b-c r$. These results suggest that $q n r S$ and $a c c\left(6^{\prime}\right)-I b-c r$ are located in distinct plasmids, which is 
different from previous studies that $q n r$ alleles are frequently co-expressed with $a c c\left(6^{\prime}\right)-I b-c r$ on the same plasmid [27, 38]. Interestingly, all 19 PQMR-determinantsproducers in cluster $\mathrm{C}$ are also $b \mathrm{l}_{\mathrm{CTX}-\mathrm{M}}$-positive and two transconjugants (KPN-66 and KPN-88) co-carry qnrS and bla $_{\text {CTX-M }}$, indicating a significant correlation between the two determinants among these $\mathrm{KP}$ isolates.

Isolates producing $16 \mathrm{~S}$ rRNA methylase frequently exhibit high level of resistance to almost all clinically important aminoglycosides through methylation of the aminoglycoside-binding site [39]. The resistance mechanism caused by $16 \mathrm{~S}$ rRNA methylase has been reported in $\mathrm{KP}$, and the prevalence of $16 \mathrm{~S}$ rRNA methylase genes among clinical KP isolates in China is increasing [40, 41]. KPC-KP isolates are multi-drug resistant, but are usually susceptible to aminoglycosides [42-44]. Aminoglycosides also have a significantly higher microbiologic clearance rate than polymyxin B or tigecycline [45]. Here, 37.0\% (20/54) of RP-KP showed strong resistance to amikacin (100\%) and tobramycin (100\%). Co-production of $16 \mathrm{~S}$ rRNA methylases in KPC-KP could leave limited therapeutic choices for antibacterial treatment and might be associated with higher mortality in this study.

\section{Conclusions}

In summary, we reported a nosocomial outbreak of KPC-KP with clonal replacement and a new sequence type (ST2040) of KP in our hospital. ST11 is the dominant clone. The outbreak mainly occurred in ICU wards. The clonal spread was responsible for this outbreak. Our study also suggested that a high degree of awareness and surveillance of KPC-KP should be given to avoid potential outbreaks, especially in ICU wards.

\section{Abbreviations}

CLSI: Clinical and laboratory standards institute; ICU: Intensive care unit; KPC: Klebsiella pneumoniae carbapenemase; KPC-KP: KPC-producing Klebsiella pneumoniae; MIC: Minimum inhibitory concentration; MLST: Multi-locus sequence typing; PBRT: PCR-based replicon typing; PFGE: Pulse field gel electrophoresis; PMQR: Plasmid-mediated quinolone resistance; rDNA: ribosomal deoxyribonucleic acid; rRNA: ribosomal ribonucleic acid

\section{Acknowledgements}

Not applicable.

\section{Availability of data and materials}

The data and materials can be obtained on request from the authors.

\section{Authors' contributions}

SC designed the study and drafted the manuscript. $Y L$ and $X Y$ performed the experiments and analyzed the data. LZ collected the data. All authors read and approved the final version of this manuscript.

\section{Competing interests}

The authors declare that they have no competing interests.

\section{Consent for publication}

Not applicable.

Ethics approval and consent to participate Not required for this study.

\section{Publisher's Note}

Springer Nature remains neutral with regard to jurisdictional claims in published maps and institutional affiliations.

Received: 19 October 2016 Accepted: 16 May 2017

Published online: 23 May 2017

\section{References}

1. Munoz-price LS, Poirel L, Bonomo RA, Schwaber MJ, Daikos GL, Cormican M, Cornaglia G, Garau J, Gniadkowski M, Hayden MK, Kumarasamy K, Livermore DM, Maya JJ, Nordmann P, Patel JB, Paterson DL, Pitout J, Villegas MV, Wang H, Woodford N, Quinn JP. Clinical epidemiology of the global expansion of Klebsiella pneumoniae carbapenemases. Lancet Infect Dis. 2013;13:785-96.

2. Borer A, Saidel-Odes L, Riesenberg K, Eskira S, Peled N, Nativ R, Schlaeffer F, Sherf M. Attributable mortality rate for carbapenem-resistant Klebsiella pneumoniae bacteremia. Infect Control Hosp Epidemiol. 2009;30:972-6.

3. Hu F, Zhu D, Wang F, Jiang X, Sun Z, Chen Z, Hu Z, Li J, Xie Y, Kang M, Xu Y, Zhang $X$, Zhang C, Ji P, Wang C, Wang A, Ni Y, Sun J, Yu Y, Lin J, Chu Y, Tian S, Xu Y, Shen J, Shan B, Du Y, Zhuo C, Su D, Zhang H, Kong J, Wei L, Wu L, Hu Y, Ai X. CHINET 2013 surveillance of bacterial resistance in China. Chin J Infect Chemother. 2014;14:365-74.

4. Qi Y, Wei Z, Ji S, Du X, Shen P, Yu Y. ST11, the dominant clone of KPCproducing Klebsiella pneumoniae in China. J Antimicrob Chemother. 2011;66:307-12

5. Adler A, Khabra E, Paikin S, Carmeli Y. Dissemination of the blaKPC gene by clonal spread and horizontal gene transfer: comparative study of incidence and molecular mechanisms. J Antimicrob Chemother. 2016;71:2143-6.

6. Wei ZQ, Du XX, Yu YS, Shen P, Chen YG, LJ LI. Plasmid-mediated KPC-2 in a Klebsiella pneumoniae isolate from China. Antimicrob Agents Chemother. 2007;51:763-5.

7. Cai JC, Zhou HW, Zhang R, Chen GX. Emergence of Serratia Marcescens, Klebsiella pneumoniae, and Escherichia coli isolates possessing the plasmidmediated carbapenem-hydrolyzing $\beta$-Lactamase KPC-2 in intensive care units of a Chinese hospital. Antimicrob Agents Chemother. 2008:52:2014-8.

8. Shen P, Wei Z, Jiang Y, Du X, Ji S, Yu Y, Li L. Novel genetic environment of the carbapenem-hydrolyzing $\beta$-Lactamase KPC-2 among Enterobacteriaceae in China. Antimicrob Agents Chemother. 2009;53:4333-8.

9. Qi Y, Wei Z, Li L, Ji S, Du X, Shen P, Yu Y. Detection of a common plasmid carrying bla KPC-2 $_{2}$ in Enterobacteriaceae isolates from distinct cities in China. Microb Drug Resist. 2010;16:297-301.

10. Yang Q, Wang H, Sun H, Chen H, Xu Y, Chen M. Phenotypic and genotypic characterization of Enterobacteriaceae with decreased susceptibility to carbapenems: results from large hospital-based surveillance studies in China. Antimicrob Agents Chemother. 2010;54:573-7.

11. Chen S, Hu F, Xu X, Liu Y, Wu W, Zhu D, Wang H. High prevalence of KPC-2type carbapenemase coupled with CTX-M-type extended-spectrum $\beta$ lactamases in carbapenem-resistant Klebsiella pneumoniae in a teaching hospital in China. Antimicrob Agents Chemother. 2011;55:2493-4.

12. Wang Y, Cao W, Zhu X, Chen Z, Li L, Zhang B, Wang B, Tian L, Wang F, Liu C, Sun Z. Characterization of a novel Klebsiella pneumoniae sequence type 476 carrying both b/a $a_{\mathrm{KPC}-2}$ and bla $a_{\mathrm{MP}-4}$. Eur J Clin Microbiol Infect Dis. 2012;31:1867-72.

13. Sheng JF, Li JJ, Tu S, Sheng ZK, Bi S, Zhu MH, Shen XM, Li LJ. bla KPC and $r m t B$ on a single plasmid in Enterobacter amnigenus and Klebsiella pneumoniae isolates from the same patient. Eur J Clin Microbiol Infect Dis. 2012;31:1585-91.

14. Zhang R, Wang XD, Cai JC, Zhou HW, Lv HX, Hu QF, Chen GX. Outbreak of Klebsiella pneumoniae carbapenemase 2-producing K. pneumoniae with high qur prevalence in a Chinese hospital. J Med Microbiol. 2011;60:977-82.

15. Tang HJ, Chen YT, Chiang T, Fung CP, Chuang YC, Kristopher SL. Identification of the first imported KPC-3 Klebsiella pneumoniae form the USA to Taiwan. Int J Antimicrob Agents. 2014;44:431-5.

16. Xing C, Ge B, Yu K, Gao S, Liang B, Ye H. Bloodstream infections caused by Klebsiella pneumoniae carbapenemase 2-producing K.pneumoniae at a hematology Department in Wenzhou, China. Intern Med. 2016;55:2087-91.

17. Zhou T, Zhang Y, Li M, Yu X, Sun Y, Xu J. An outbreak of infections caused by extensively drug-resistant Klebsiella pneumoniae strains during a short period of time in a Chinese teaching hospital: epidemiology study and molecular characteristics. Diagn Microbiol Infect Dis. 2015;82:240-4. 
18. Jiang $Y$, Wei Z, Wang Y, Hua X, Feng Y, Yu Y. Tracking a hospital outbreak of KPC-producing ST11 Klebsiella pneumoniae with whole genome sequencing. Clin Mirobiol Infect. 2015;21:1001-7.

19. Hong SS, Kim K, Huh JY, Jung B, Kang MS, Hong SG. Multiplex PCR for rapid detection of genes encoding class a carbapenemases. Ann Lab Med. 2012;32:359-61.

20. Poirel L, Walsh TR, Cuvillier V, Nordmann P. Multiplex PCR for detection of acquired carbapenemase genes. Diagn Microbiol Infect Dis. 2011;70:119-23.

21. Dallenne C, Da Costa A, Decre D, Favier C, Arlet G. Development of a set of multiplex PCR assays for the detection of genes encoding important beta-lactamases in Enterobacteriaceae. J Antimicrob Chemother. 2010;65:490-5.

22. Edelsin M, Pimkin M, Palagin I, Edelstein I, Stratchounski L. Prevalence and molecular epidemiology of CTX-M extended-spectrum ß-Lactamaseproducing Esherichia coli and Klebsiella pneumonia in Russian hospitals. Antimcrob Agents Chenother. 2003;47:3724-32.

23. Poirel L, Potron A, Nordmann P. OXA-48-like carbapenemases: the phantom menace. J Antimicrob Chemother. 2012;67:1597-606.

24. Yamane K, Wachino J, Suzuki S, Shibata N, Kato H, Shibayama K, Kimura K, Kai K, Ishikawa S, Ozawa Y, Konda T, Arakawa Y. 16 S rRNA Methylaseproducing, gram-negative pathogens Japan. Emerg Infect Dis. 2007;13:642-6.

25. Zhou Y, Yu H, Guo Q, Xu X, Ye X, Wu S, Guo Y, Wang M. Distribution of 165 rRNA methylases among different species of gram-negative bacilli with high-level resistance to aminoglycosides. Eur J Clin Microbiol Infect Dis. 2010;29:1349-53.

26. Perez FJ, Hanson ND. Detection of plasmid-mediated AmpC $\beta$ lactamase genes in clinical isolates by using multiplex PCR. J Clin Microbiol. 2002;40:2153-62.

27. Luo $Y$, Yang J, Zhang Y, Ye L, Wang L, Guo L. Prevalence of B-lactamases and 165 rRNA methylase genes amongst clinical Klebsiella pneumoniae isolates carrying plasmid-mediated quinolone resistance determinants. Int J Antimicrob Agents. 2011;37:352-5.

28. Clinical Laboratory Standards Institute (CLSI). Performance Standards for Antimicrobial Susceptibility Testing. 24th Informational Supplement M100S24. Wayne: CLSI; 2014.

29. Pereira PS, Borghi M, de Araújo CF, Aires CA, Oliveira JC, Asensi MD, CarvalhoAssef AP. Clonal dissemination of OXA-370-producing Klebsiella pneumoniae in Rio de Janeiro, Brazil. Antimicrob Agents Chemother. 2015;59:4453-6.

30. Diancourt L, Passet V, Verhoef J, Grimont PA, Brisse S. Multilocus sequence typing of Klebsiella pneumoniae nosocomial isolates. J Clin Microbiol. 2005; 43:4178-82.

31. Carattoli A, Bertini A, Villa L, Falbo V, Hopkins KL, Threlfall EJ. Identification of plasmids by PCR-based replicon typing. J Microbiol Methods. 2005;63:219-28.

32. Yang J, Ye L, Guo L, Zhao Q, Chen R, Luo Y, Chen Y, Tian S, Zhao J, Shen D, Han L. A nosocomial outbreak of KPC-2-producing Klebsiella pneumoniae in a Chinese hospital: dissemination of ST11 and emergence of ST37, ST392 and ST395. Clin Microbiol Infect. 2013;19:E509-15.

33. Li JJ, Sheng ZK, Deng M, Bi S, Hu FS, Miao HF, Ji ZK, Sheng JF, Li LJ. Epidemic of Klebsiella pneumoniae ST11 clone coproducing KPC-2 and $16 \mathrm{~S}$ rRNA methylase RmtB in a Chinese university hospital. BMC Infect Dis. 2012; 12:373.

34. Giamarellos-Bourboulis EJ, Plachouras D, Tzivra A, Kousoulas V, Bolanos N, Raftogiannis M, Galani I, Dontas I, Dionyssiou-Asteriou A, Giamarellou H. Stimulation of innate immunity by susceptible and multidrugresistant Pseudomonas aeruginosa an in vitro and in vivo study. Clin Exp. 2004;135:240-6.

35. Shin J, Ko KS. Comparative study of genotype and virulence in CTX-Mproducing and non-extended-spectrum- $\beta$-lactamase-producing Klebsiella pneumoniae isolates. Antimicrob Agents Chemother. 2014;58:2463-7.

36. Shin J, Choi MJ, Ko KS. Replicon sequence typing of IncF plasmids and the genetic environments of blaCTX-M-15 indicate multiple acquisitions of blaCTX-M-15 in Escherichia coli and Klebsiella pneumoniae isolates from South Korea. J Antimicrob Chemother. 2012;67:1853-7.

37. Hammond DS, Harris T, Bell J, Turnidge J, Giffard PM. Selection of SHV extended-spectrum- $\beta$-lactamase-dependent cefotaxime and ceftazidime resistance in Klebsiella pneumoniae requires a plasmid-borne bla $a_{\mathrm{SHV}}$ gene. Antimicrob Agents Chemother. 2008;52:441-5

38. Jiang Y, Zhou Z, Qian Y, Wei Z, Yu Y, Hu S, Li L. Plasmid-mediated quinolone resistance determinants qnr and $\operatorname{acc}\left(6^{\prime}\right)-1 b-c r$ in extendedspectrum $\beta$-lactamase-producing Escherichia coli and Klebsiella pneumoniae in China. J Antimicrobial Chemoth. 2008;61:1003-6.
39. Doi Y, Arakawa Y. 165 ribosomal RNA methylation: emerging resistance mechanism against aminoglycosides. Clin Infect Dis. 2007:45:88-94.

40. Wu Q, Zhang Y, Han L, Sun J, Ni Y. Plasmid-mediated 16S rRNA methylases in aminoglycoside-resistant Enterobacteriaceae isolates in shanghai, China. Antimicrob Agents Chemother. 2009;53:271-2.

41. Yang J, Ye L, Wang W, Luo Y, Zhang Y, Han L. Diverse prevalence of $16 \mathrm{~S}$ rRNA methylase genes armA and rmtB amonst clinical multidrug-resistant Escherichia coli and Klebsiella pneumoniae isolates. Int J Antimicrob Agents. 2011;38:348-51.

42. Samuelsen O, Naseer U, Tofteland S, Skutlaberg DH, Onken A, Hjetland R, Sundsfjord A, Giske CG. Emergence of clonally related Klebsiella pneumoniae isolates of sequence type 258 producing plasmid-mediated KPC carbapenemase in Norway and Sweden. J Antimicrob Chemother. 2009;63:654-8.

43. Bogdanovich T, Adams-Haduch JM, Tian GB, Nguyen MH, Kwak EJ, Muto CA, Doi Y. Colistin-resistant, Klebsiella pneumoniae Carbapenemase (KPC)producing Klebsiella pneumoniae belonging to the international epidemic clone ST258. Clin Infect Dis. 2011;53:373-6.

44. Daly MW, Riddle DJ, Ledeboer NA, Dunne WM, Ritchie DJ. Tigecycline for treatment of pneumonia and empyema caused by carbapenemase producing Klebsiella pneumoniae. Pharmacotherapy. 2007;27:1052-7.

45. Satlin MJ, Kubin CJ, Blumenthal JS, Cohen AB, Furuya EY, Wilson SJ, Jenkins SG, Calfee DP. Comparative effectiveness of aminoglycosides, polymyxin B, and tigecycline for clearance of carbapenem-resistant Klebsiella pneumoniae from urine. Antimicrob Agents Chemother. 2011;55:5893-9.

\section{Submit your next manuscript to BioMed Central and we will help you at every step:}

- We accept pre-submission inquiries

- Our selector tool helps you to find the most relevant journal

- We provide round the clock customer support

- Convenient online submission

- Thorough peer review

- Inclusion in PubMed and all major indexing services

- Maximum visibility for your research

Submit your manuscript at www.biomedcentral.com/submit

) Biomed Central 